\title{
A Case with Marshall-Smith Syndrome without Life-threatening Complications
}

\author{
Takuo Kubota $^{1}$, Noriyuki Namba ${ }^{1,3}$, Shigeo Nakajima ${ }^{1}$, Hiroshi Arai ${ }^{2}$ and Keiichi Ozono ${ }^{1}$ \\ ${ }^{1}$ Department of Pediatrics, Osaka University Graduate School of Medicine, Osaka, \\ ${ }^{2}$ Department of Pediatric Neurology, Bobath Memorial Hospital, Osaka, \\ ${ }^{3}$ The First Department of Oral and Maxillofacial Surgery, Osaka University Graduate School of Dentistry, Osaka, \\ Japan
}

\begin{abstract}
We present a case of Marshall-Smith syndrome, characterized by accelerated osseous maturation, craniofacial anomalies, failure to thrive, psychomotor delay, pulmonary dysfunction, and limited life expectancy. Recently, Marshall-Smith syndrome's clinical variability is becoming apparent and the phenotype is expanding. Our case had craniofacial anomalies, including prominent eyes, external strabismus, blue sclera, flat nasal bridge, and micrognatia. Moreover, she showed extension of the hip joint, hypotonia, and arachnodactyly. She was referred to our hospital due to dysmorphic facies at 7 mo and overgrowth was noticed with a height of $74.2 \mathrm{~cm}$ (+2.7 SD). Radiographic surveys demonstrated accelerated osseous maturation with a bone age of $1 \mathrm{yr} 6$ mo at the chronological age of 10 mo and broad proximal phalanges. We diagnosed this case as Marshall-Smith syndrome according to clinical features and radiographic findings. Except for one episode of broncho-pulmonitis which required hospitalization, she has not had other severe infections up to date. Presently, she is $1 \mathrm{yr} 9 \mathrm{mo} ; 88.0 \mathrm{~cm}(+2.1 \mathrm{SD})$ and 10.4 $\mathrm{kg}(-0.3 \mathrm{SD})$. This case suggests that there are patients with Marshall-Smith syndrome without lifethreatening complications.
\end{abstract}

Key words: Marshall-Smith syndrome, accelerated osseous maturation, growth, complications

\section{Introduction}

Marshall-Smith syndrome (MIM 602535) was described by Marshall et al. in 1971 (1). This syndrome is characterized by accelerated osseous maturation, accelerated prenatal linear growth, broad phalanges, craniofacial anomalies, failure to thrive, pulmonary dysfunction, hypotonia, and

Correspondence: Dr. Keiichi Ozono, Department of Pediatrics, Osaka University Graduate School of Medicine, 22 Yamada-oka, Suita City, Osaka 565-0871, Japan

E-mail: keioz@ped.med.osaka-u.ac.jp psychomotor delay. The craniofacial anomalies include prominent forehead, prominent eyes, blue sclera, small nose with anteverted nares, and micrognatia (2). More than 20 cases have been published so far and 4 Japanese cases have been reported. Most patients with Marshall-Smith syndrome have a severe clinical course and die due to respiratory problems in the first 3 years of life (3). However, as more cases are reported, in which long survivals are included, the clinical variability of Marshall-Smith syndrome is becoming apparent and the phenotype is expanding (4-6). The pathogenesis is currently unknown. We present a 

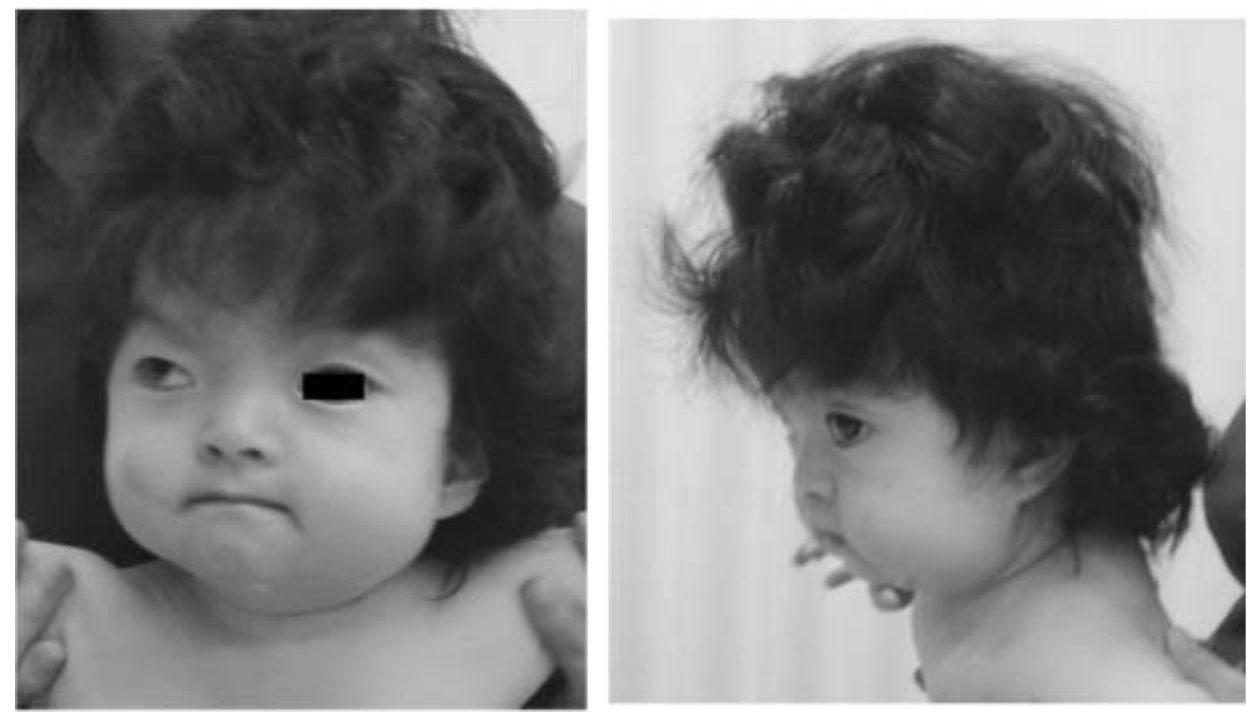

Fig. 1 Facial appearance of the patient at 10 mo old (Permission was obtained from the parents).

case with characteristic features of this rare syndrome and who has reached 1 yr 9 mo without life-threatening complications.

\section{Case Report}

The patient is a 1-yr 9-mo-old Japanese female, the firstborn child of healthy, non-consanguineous parents. The family history is unremarkable. The child was delivered at 39 wk of gestation by an emergency cesarean section because of prolonged delivery, with a length of $50.0 \mathrm{~cm}(+0.3 \mathrm{SD})$, a weight of $3,784 \mathrm{~g}(+2.1 \mathrm{SD})$, and a head circumference of $33.9 \mathrm{~cm}(+0.7 \mathrm{SD})$. She had no respiratory complications and no apparent sucking problems. Hypotonia and exophthalmos were noticed at 1 mo. She was referred to our hospital due to dysmorphic facies at $7 \mathrm{mo}$ and overgrowth was noted, height of $74.2 \mathrm{~cm}(+2.7 \mathrm{SD})$. Physical examination at 10 mo showed a height of $77.6 \mathrm{~cm}(+2.6 \mathrm{SD})$, a weight of $8,125 \mathrm{~g}(-0.4 \mathrm{SD})$, a head circumference of $43.3 \mathrm{~cm}(-0.7 \mathrm{SD})$, and an arm span of $77.5 \mathrm{~cm}$. The craniofacial features (Fig. 1) included anterior fontanelle closure, flattened occiput, prominent eyes, external strabismus, blue sclera, hypertelorism, flat nasal bridge, small nose with anteverted nares, low-set ears, high arched palate, divided uvula, micrognatia, and hypertrichosis. In addition, she showed pectus excavatum, kyphosis, extension of the hip joints, hypotonia, arachnodactyly, and clinodactyly of the right fifth finger. She had no heart murmurs, normal vesicular sounds, normal external genitalia, and normal patella tendon reflex. Radiographic surveys (Fig. 2) demonstrated that the skeletal age was 1 yr 6 mo at the chronological age of $10 \mathrm{mo}$, and $3 \mathrm{yr} 3 \mathrm{mo}$ at the chronological age of 1 yr 9 mo. The hands showed broad proximal and narrow distal phalanges besides advanced skeletal maturation. Other findings included shallow orbits, thin ribs, scoliosis, and mild irregular epiphysis and metaphysis. Vertebral bodies appeared normal. CT scan of the head showed no remarkable anomalies. Routine laboratory examinations were unremarkable. Chromosome analysis showed 46, XX, inv (9) (p11q13), the most common normal variant seen in 1 to $2.5 \%$ of the general population (7). This variant is unrelated to phenotype, reproduction, and chromosome non-disjunction. 

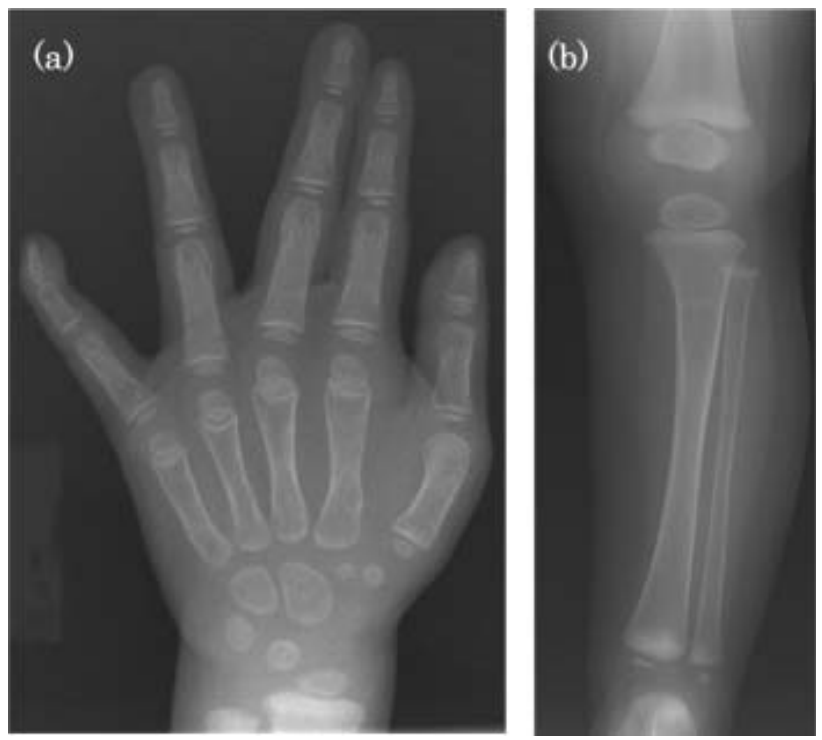

Fig. 2 Radiography of the hand at 1 yr and 9 mo (a) and lower limb 10 mo (b) old.
The patient's IGF-1 level was not elevated at 149 $\mathrm{ng} / \mathrm{ml}$ (normal range: $28-262 \mathrm{ng} / \mathrm{ml}$ ) and the values of other endocrine hormones were within normal range. We diagnosed this case as MarshallSmith syndrome according to the clinical features and radiographic findings of the hand (Table 1). Though the patient has had an episode of bronchopneumonitis which required hospitalization, she had no other severe respiratory problems. Presently, she is 1 yr 9 mo old, with a height of 88.0 $\mathrm{cm}(+2.1 \mathrm{SD})$ and a weight of $10.4 \mathrm{~kg}(-0.3 \mathrm{SD})$ (Fig. 3). She has mild psychomotor delay, but can walk alone and speak several words though with inarticulate pronunciation. Her general health is good.

\section{Discussion}

Our patient has the features (Table 1) of the Marshall-Smith syndrome, including

Table 1 Features of Marshall-Smith syndrome

\begin{tabular}{lcc}
\hline Clinical findings & Previous reports & This patient \\
\hline Accelerated osseous maturation & $22 / 22$ & + \\
Broad phalanges & $21 / 21$ & + \\
Failure to thrive & $14 / 17$ & - \\
Neurodevelopmental anomalies & $16 / 17$ & + \\
Structural brain anomalies & $10 / 18$ & - \\
Respiratory tract anomalies & $16 / 21$ & - \\
Recurrent pneumonia & $14 / 21$ & - \\
Pulmonary hypertension & $4 / 20$ & $?$ \\
Death in early infancy & $12 / 21$ & - \\
Prominent forehead & $19 / 22$ & - \\
Small face & $16 / 22$ & - \\
Prominent eyes & $20 / 22$ & + \\
Blue sclerae & $11 / 22$ & + \\
Flat nasal bridge & $21 / 22$ & + \\
Anteverted nares & $18 / 19$ & + \\
Micrognathia & $18 / 22$ & + \\
Glossoptosis & $6 / 21$ & - \\
Choanal atresia/stenosis & $4 / 21$ & - \\
Hypertrichosis & $11 / 22$ & + \\
Umbilical hernia & $8 / 21$ & - \\
\hline
\end{tabular}

Adapted from Summers et al. (2). 


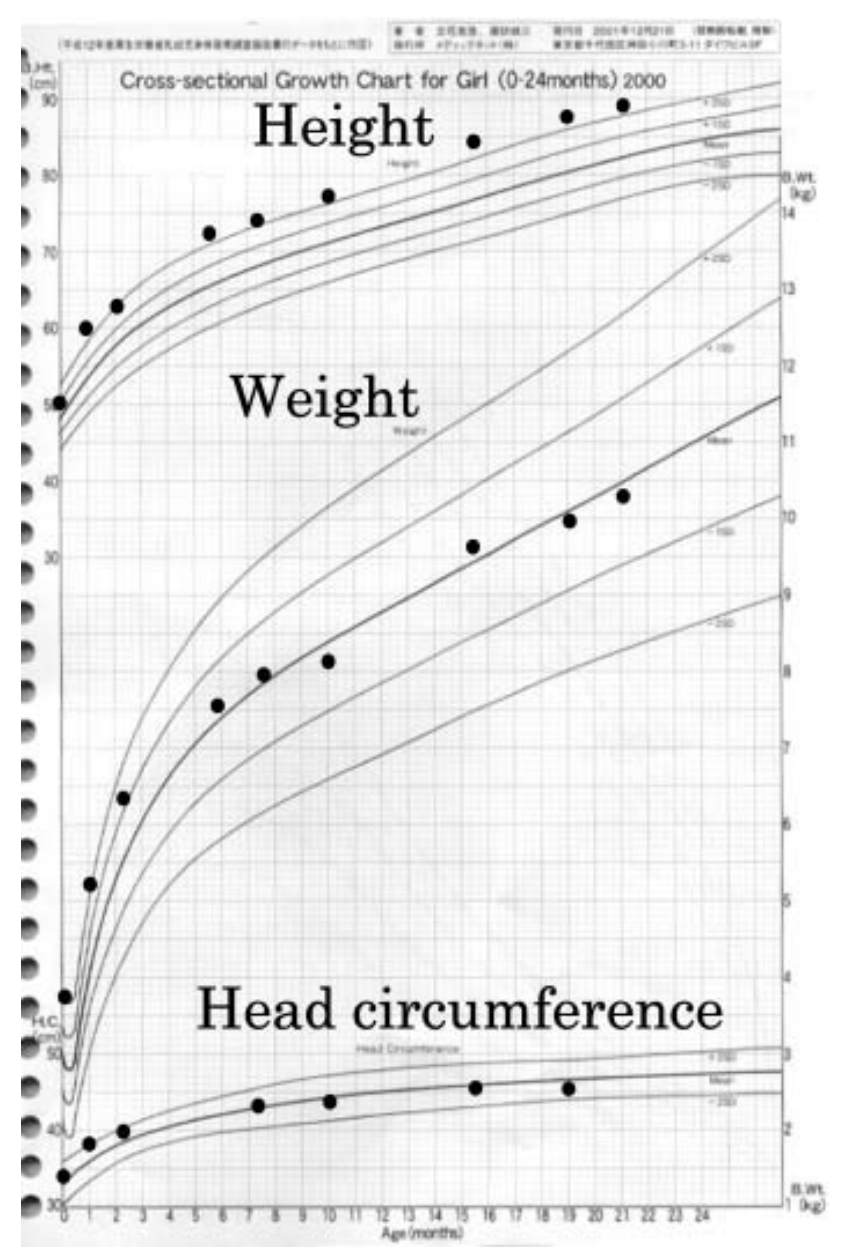

Fig. 3 Growth chart.

characteristic facies, accelerated osseous maturation, anomalies of the phalanges, and mental retardation $(1,2)$. Despite the fact that most patients with Marshall-Smith syndrome described so far have respiratory problems (8), our patient has suffered from broncho-pneumonitis only once. Sperli et al. have reported the case of a 5-yr-old boy with typical features of the MarshallSmith syndrome, but without respiratory difficulties in early infancy (5).

Most previous reports also describe significant failure to thrive $(1,2)$. However, this does not apply to our patient, probably due to absence of upper airway obstruction. Birth length of Marshall-
Smith syndrome, in many cases, has been reported to be in the normal range or above. However, most cases fail to grow at a normal rate due to respiratory problems and failure to thrive, and therefore become relatively short with poor weight gain from infancy in spite of onset of accelerated prenatal linear growth. As mentioned above, our patient did not have these problems, and she has grown well and was $88.0 \mathrm{~cm}(+2.1 \mathrm{SD})$ in height at 1 yr 9 mo. We tested for endocrinological abnormalities and found that the serum level of IGF-1 was within a normal range. Other syndromes with advanced bone age and overgrowth including Sotos and Weaver syndromes were also considered as differential diagnoses, but were excluded based on clinical findings and our experience of caring for these patients (9). Our findings suggest that MarshallSmith syndrome patients could overgrow after birth with good nutrition and respiratory conditions.

Diab et al. recently emphasized osseous fragility as a clinically significant problem in Marshall-Smith syndrome, describing a case with multiple fractures and skeletal anomalies including metaphysis and epiphysis (10). Butler also described a child having osteopenia and fractures (11). Though our patient has had no fractures, since she has shown mild irregularity in the epiphysis and metaphysis, bone strength should be followed up.

In summary, we report a case with features of Marshall-Smith syndrome, including characteristic facies, accelerated osseous maturation and phalangeal anomalies. This case suggests that there are patients with MarshallSmith syndrome without life-threatening complications.

\section{Acknowledgements}

We wish to thank Dr. Gen Nishimura for constructive discussions. 


\section{References}

1. Marshall RE, Graham CB, Scott RC, Smith DW. Syndrome of accelerated skeletal maturation and relative failure to thrive. J Pediatr 1971;78:95101.

2. Summers DA, Cooper HA, Butler MG. MarshallSmith syndrome: case report of a newborn male and review of the literature. Clin Dysmorph 1999;8:207-10.

3. Roodhooft AM, Van Acker KJ, Van Thienen MN, Martin JJ, Ceuterick C. Marshall-Smith syndrome: new aspects. Neuropediatrics 1988;19:179-82.

4. Washington K, Rourk MH, McDonald D, Oldham KT. Inflammatory cloacogenic polyp in a child: part of the spectrum of solitary rectal ulcer syndrome. Pediatr Pathol 1993;13:409-14.

5. Sperli D, Concolino D, Barbato C, Strisciuglio P, Andria G. Long survival of a patient with MarshallSmith syndrome without respiratory complications. J Med Genet 1993;30:877-9.

6. Williams DK, Carlton DR, Green SH, Pearman K,
Cole TRP. Marshall-Smith syndrome: the expanding phenotype. J Med Genet 1997;34:8425.

7. Muller HJ, Klinger HP, Glasser M. Chromosome polymorphism in a human newborn population. Cytogenet Cell Genet 1975;15:239-55.

8. Johnson JP, Carey JC, Glassy FJ, Paglieroni T, Lipson MH. Marshall-Smith syndrome: two case reports and a review of pulmonary manifestations. Pediatrics 1983;71:219-23.

9. Miyoshi Y, Taniike M, Mohri I, Mushiake S, Nakajima S, Matsumoto N, et al. Hormonal and genetical assessment of a Japanese girl with Weaver syndrome. Clin Pediatr Endocrinol 2004;13:17-23.

10. Diab M, Raff M, Gunther DF. Osseous fragility in Marshall-Smith syndrome. Am J Med Genet 2003; 119A: 218-22.

11. Butler MG. Marshall-Smith syndrome: follow-up report of a four and a half year old male. (Letter) Am J Med Genet 2004;126A:329-30. 